Vol. 2, n. 3 - Edição Especial: Ciclos Formativos em Ensino de Ciências.

\title{
Minha primeira experiência como Professora de Biologia: desastres e esperanças
}

\author{
My first experience as a biology teacher: disasters and hopes \\ Naiára Berwaldt Wust (nayara.wust@gmail.com) \\ Universidade Federal da Fronteira Sul - UFFS
}

\begin{abstract}
Resumo: Este relato de experiência tem como objetivo apresentar e discutir a experiência de elaboração de um planejamento de aulas direcionadas ao $2^{\circ}$ ano do Ensino Médio para o componente curricular escolar Biologia. O projeto se deu na elaboração de um plano de aula, junto com ele slides, vídeo e atividades para a aula, para finalizar o trabalho, foi gravado um vídeo para avaliarmos a nossa posição como docentes. A elaboração desta atividade demonstrou que ao trazermos temas relacionados a desastres ambientais, e tentar compreendê-los, podemos fazer um determinado olhar para a realidade, colocando em pauta a discussão sobre a concepção de vida e a forma como ela se constituiu no planeta. Podemos então confirmar que o Projeto Interdisciplinar (PI) desenvolvido como projeto pedagógico temático do Curso de Ciências Biológicas - Licenciatura, realizado em conjunto com componentes curriculares da $3^{\text {a }}$ fase do curso pode surtir efeito mais satisfatório do que o trabalho realizado isoladamente dos componentes, que não conta com o planejamento mais detalhado e objetivo. No PI, aprendem e ensinam professores formadores, licenciandos e estudantes das escolas de atuação, na ideia de melhor ensinar para bem aprender.
\end{abstract}

Palavras-chave: Planejamento; Didática; Interdisciplinaridade; Desastre Ambiental.

Abstract: This experience report aims to presente and discuss the experience of developing a planning of classes directed to the 2 nd year of high school for the curriculum component Biology. The project took place in the elaboration of a lesson plan, along with slides, video and activities for the class, to finish the work, a video was recorded toevaluate our position as teachers. The elaboration of this activity demonstrated that by bringing themes related to environmental d-isasters, and trying to understand them, we can take a determined look at reality, putting the discussion about the conception of life and the way it was constituted on the planet. We can then confirm that the Interdisciplinary Project (IP) developed as a thematic pedagogical project of the Biological Sciences Course - Undergraduate Program, carried out in conjunction with curricular components of the third phase of the course may have a more satisfactory effect than the work carried out in isolation from the components, which do not. Has the most detailed and objective planning. In PI, they learn and teach teacher trainers, graduates and students of acting schools, in the idea of better teaching for good learning. 
Vol. 2, n. 3 - Edição Especial: Ciclos Formativos em Ensino de Ciências.

Keyword: Planning; Didactics; Interdisciplinarity; Environmental disaster.

\section{O CONTEXTO DA PRODUÇÃO DE MINHA EXPERIÊNCIA}

A temática escolhida para elaboração do relato, foi a minha primeira experiência em sala de aula, no qual contempla as atividades desenvolvidas junto ao projeto interdisciplinar semestral (UFFS, 2013) do Curso de Ciências Biológicas - Licenciatura, da Universidade Federal da Fronteira Sul (UFFS), Campus Cerro Largo, elaborado com a coordenação do componente curricular de Prática de Ensino em Ciências e Biologia III: Didática e Metodologia do ensino de Ciências e Biologia com interligação dos demais componentes do $3^{\circ}$ semestre especialmente com Ecologia de organismos e populações. Assim, foi planejada e implementada a produção e desenvolvimento de um conjunto de aulas, com 4 horas-aula direcionadas ao $2^{\circ}$ ano do Ensino Médio para o componente curricular escolar Biologia. O tema abordado e discutido foi o desastre nuclear de Fukushima, ocorrido em 11 de março de 2011, no Japão.

No ambiente escolar o planejamento é uma peça fundamental, nele há a organização do conteúdo para o ano letivo, que está presente também em quase todas as nossas ações, pois ele norteia a realização das atividades, sendo essencial em diferentes setores da vida social, e na atividade docente. De acordo com Libâneo (1994, p. 221).

O planejamento escolar é uma tarefa docente que inclui tanto a previsão das atividades didáticas em termos de organização e coordenação em face dos objetivos propostos, quanto a sua revisão e adequação no decorrer do processo de ensino.

Como vimos o papel do planejamento é de grande importância, mas não quer dizer que devemos seguir tal e qual está ali, podemos de forma inovadora utilizar de outras práticas, meios que não interfiram o contexto do que está sendo ensinado, algo positivo que ajuda no andamento da aula, é quando os alunos estão cientes dos assuntos do nosso cotidiano, assim participando ativamente e formulando seu pensamento crítico, saindo da sua zona de conforto o qual o aluno está familiarizado (GÜLLICH, 2013). 
Vol. 2, n. 3 - Edição Especial: Ciclos Formativos em Ensino de Ciências.

Como havia descrito o objetivo seria a elaboração do plano de aula, o assunto trabalhado o desastre Nuclear de Fukushima que aconteceu no Japão em 2011. Em sua elaboração buscou apresentar o processo, as causas e os efeitos do acidente nuclear de Fukushima, seu impacto e consequências para a fauna, a flora e humanidade. Segundo a visão de Bochniack (1992, p. 6):

\begin{abstract}
A interdisciplinaridade deve começar na mente das pessoas envolvidas no processo, a primeira mudança necessária para viabilizar o processo de diálogo entre os conhecimentos é a credibilidade do professor em sua função de modificador da sociedade na qual atua. Cabe ao professor preparar as gerações futuras para sua função de "fazedores" da história e construtores do conhecimento verdadeiro.
\end{abstract}

Acredito que a interdisciplinaridade deve ser entendida como um instrumento para aproximar o conhecimento formalizado à prática cotidiana, sendo que o objetivo do projeto foi a elaboração do plano de aula o que é muito importante não apenas planejar e sim pôr em prática como foi realizado, pois ensinar nos possibilita aprender a ser docentes.

\title{
2. COMO TUDO FOI PENSADO: APRESENTANDO A PRÁTICA
}

O planejamento foi produzido na UFFS em grupo, tendo como orientadores os professores formadores. Assim, a partir de um tema desenvolvemos um plano de aula para 4 horas/aula, buscando explicar sobre o desastre seus prejuízos e também enfatizar a importância de cuidar o meio ambiente, e sobre as nossas ações. O Projeto Interdisciplinar possibilita durante cada semestre um novo aprendizado, enfatizando a importância de um planejamento e de boas metodologias de ensino, iniciei com uma breve busca sobre o tema, separando em categorias para iniciar de fato o plano, foi utilizado o drive para fazer a apresentação dos slides, no final do projeto após ministrada a aula, como forma de avaliarmos foi realizada uma gravação de vídeo. Ao me gravar e ver a minha postura como professora vi o quanto é importante estarmos envolvidos com o ambiente escolar durante nossa formação, por meio da gravação podemos visualizar a nossa postura em sala de aula e dicção pontos chaves para um bom docente. 
Vol. 2, n. 3 - Edição Especial: Ciclos Formativos em Ensino de Ciências.

A aula foi ministrada em uma escola pública da região das missões, para o $2^{\circ}$ ano do ensino médio, componente curricular escolar Biologia, sendo que havia 8 alunos, a professora regente da turma e mais três colegas, que junto comigo, ministraram a aula.

Para iniciar me apresentei enfatizando o objetivo naquela tarde, em seguida entreguei um breve texto para introdução. Posteriormente, por meio de slides, apresentei a aula no qual foi abordado a origem de um tsunami e terremoto, enfatizando os três exemplos de placas tectônicas, o que iniciou o acidente de Fukushima, relacionando com suas consequências tanto para os humanos como para o meio ambiente.

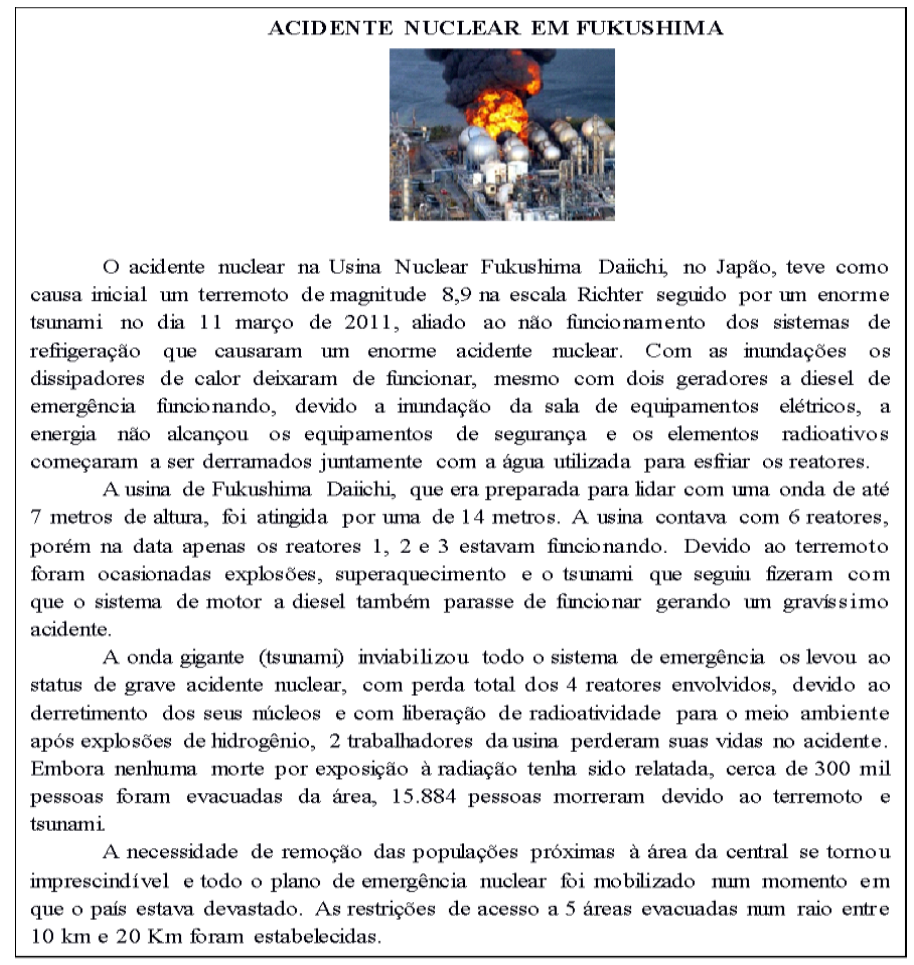

\section{1- Figura Texto de Introdução}

Em um segundo período da aula abordamos um vídeo, enfatizando tudo o que havíamos visto em aula, e algumas notícias a mais, juntamente com o vídeo foi elaborado algumas questões para serem respondidas ao longo do depoimento, com uma breve introdução. 
Vol. 2, n. 3 - Edição Especial: Ciclos Formativos em Ensino de Ciências.

Ao término do vídeo, deixamos uns 10 minutos para quem não havia conseguido responder tudo terminar, após isso comentaríamos as perguntas e respostas, cada um de forma espontânea lia sua resposta e assim conseguimos dialogar sobre o assunto respondendo as dúvidas e também perceber se já haviam domínio do assunto em termos gerais e iniciais.

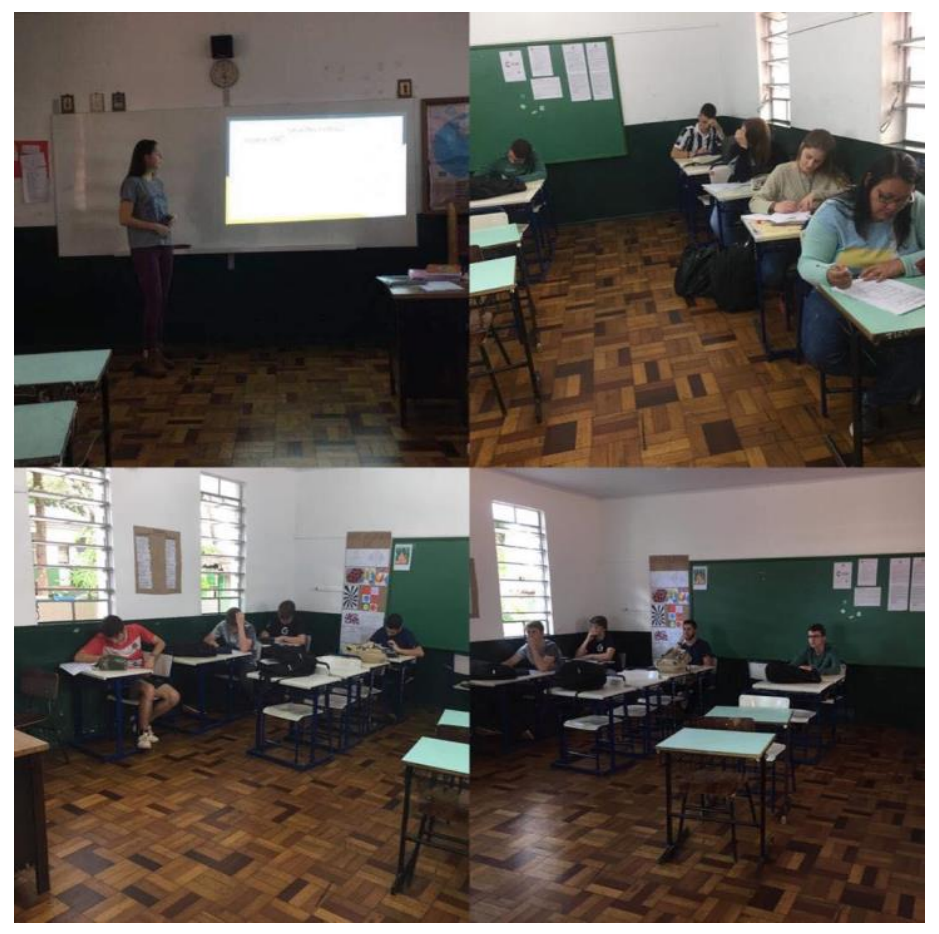

2- Figura Produção da aula

\section{DISCUTINDO A PRÁTICA PARA APRENDER COM A PRIMEIRA EXPERIÊNCIA}

Ao analisar as respostas dos alunos em relação as atividades desenvolvidas, concluo que eles conseguiram compreender o assunto estudado, entenderam a importância do estudo e quão forte é o impacto dos acidentes ambientais, e como é visto na sociedade. A terceira pergunta do questionário se referia ao Governo e suas medidas sob o acontecimento, a resposta de um dos 8 alunos responde de forma ampla a realidade do fato. 
Vol. 2, n. 3 - Edição Especial: Ciclos Formativos em Ensino de Ciências.

Resposta do aluno 3: "O Governo está censurando os fatos, tentando fazer a população achar que a gravidade do desastre não é grande. Ao ler essa resposta se passa muita coisa em mente, uma delas a preocupação, será que haverá uma solução para esse problema, as famílias poderão viver em paz em suas casas, e além disso o que estão fazendo e se estão de fato fazendo algo para solucionar, são fatos que devemos analisar e não apenas nesse local, mas o mundo todo, os desastres que vem acontecendo será que haverá soluções, e porque estão acontecendo, que futuro queremos, será que podemos pensar no nosso futuro e ficarmos em paz. Eu como discente em formação e como futura professora me preocupo muito com nosso meio ambiente e o que ele vem sofrendo é preocupante".

A última pergunta se referia aos métodos utilizados para diminuição da contaminação. Resposta do aluno 5: "Eles retiraram toneladas de terra contaminada e águas que são armazenadas em centenas de tanques e as terras em enormes bolsas".

Pensando no método utilizado descrito na resposta, não seria um método confiável de ser realizado, pois não vai haver um fim desses rejeitos, e se por algum motivo essas bolsas ou tanques rachassem ou estourassem o prejuízo seria muito maior, pelo fato de contaminar outras áreas, são essas questões e ações que são importantes serem relatadas em aula. Todos os alunos conseguiram responder as atividades, em suas respostas relataram os prejuízos a fauna, flora e como a mídia está envolvida nesses casos.

No final da aula a sensação foi de satisfação, consegui ocupar o horário destinado e cumprir com meus objetivos proposto para aquela aula. Consegui fazer com que a turma colaborasse e interagisse, talvez pelo fato de ser uma turma de poucos alunos e o conteúdo estudado ter sido um assunto de grande percussão nas mídias e redes sociais, possibilitou um bom diálogo pois a maioria estava ciente do acontecimento o que foi algo positivo para mim, pelo fato de iniciar essa caminhada que é ser professora.

A formação e o trabalho docente é uma questão importante uma vez que o mesmo deve estar consciente que sua formação deve ser contínua e está relacionada ao seu dia a dia, segundo Nóvoa (2003, p.23): “O aprender contínuo é essencial e se concentra em 
Vol. 2, n. 3 - Edição Especial: Ciclos Formativos em Ensino de Ciências.

dois pilares: a própria pessoa, como agente, e a escola como lugar de crescimento profissional permanente". Para este estudioso a formação continuada acontece de maneira coletiva e depende de experiência, reflexões como instrumentos de análise.

A elaboração desse trabalho nos mostra que ao trazermos temas relacionados a acontecimentos ambientais e tentar compreendê-los, nos coloca frente a um determinado olhar para a realidade, colocando em pauta a discussão sobre a concepção de vida e a forma de como ela se constituiu no planeta. Este tipo de abordagem também permite a relação entre o conhecimento escolar e o conhecimento trazido pelos estudantes, fazendo com que haja uma problematização da realidade por meio do momento pedagógico.

\section{CONCLUSÃO}

Concluí com êxito meu objetivo, conseguindo abordar o que foi planejado, tendo a colaboração da turma que foi um ponto muito positivo para mim iniciante. Ter realizado essa prática foi fundamental para minha formação como futura professora.

Ao elaborar o plano e colocá-lo em prática, troquei a posição de aluna para professora e isso foi de suma importância, ter o contato com a escola durante a formação possibilita uma visão e uma experiência além do que estudamos durante a nossa formação assim ao chegarmos na escola já estaremos preparados.

Podemos confirmar que o trabalho interdisciplinar no projeto temático do Curso de Ciências Biológicas (UFFS, 2018), realizado em conjunto com outras disciplinas pode surtir efeito mais satisfatório do que o trabalho realizado isoladamente sem um planejamento mais detalhado e objetivo por parte do professor formador: assim, no PI, aprendem e ensinam professores formadores, licenciandos e estudantes das escolas de atuação, na ideia de que: "para bem aprender exige-se sobretudo, saber ensinar" (GÜLLICH, 2017, p. 22).

É muito importante reconhecer a necessidade de integrar os saberes dos componentes curriculares nas atividades de sala de aula como forma de superar os 
Vol. 2, n. 3 - Edição Especial: Ciclos Formativos em Ensino de Ciências.

problemas acarretados pela fragmentação do conhecimento a fim de possibilitar a efetivação de uma prática contextualizada que assegure uma melhor aprendizagem e promova a formação humana e integral para o aluno, baseada no pensamento crítico na Ciências (BOSKZO, GÜLLICH, 2016). Neste contexto de desafios e aprendizagens é que entendi que em meio aos desastres que posso ensinar acontecem os imprevistos na docência, porém o que mais preciso é esperança para ter sempre a coragem necessária e os desafios a superar, para com isso "melhor ensinar para bem aprender".

\section{REFERÊNCIAS}

BOCHNIAK, R. Questionar o conhecimento: interdisciplinaridade na escola. São Paulo: Loyola, 1992.

BOSZKO, C.; GÜLLICH, R.I.C. O desenvolvimento do pensamento crítico em ciências: um ensaio comparativo entre estratégias de ensino em contexto brasileiro. Revista de Ensino de Biologia - REnBio, SBEnBio, Niterói-RJ. v.9, n.9, p. 2991-3003, 2016.

GÜLLICH, R. I. C.Apontamento sobre Planejamento e a Avaliação no ensino de Ciências Biológicas. In: GÜLLICH, R. I. C. Didática das ciências. Curitiba: Appris, v. 1, 2013. Cap. 1, p. 65-73.

GÜLLICH, Roque Ismael da Costa. Formação em Ciências e em Biologias: discutindo requisitos de um processo didático. In: GÜLLICH, R. I. C. HERMEL, E. E. S. (Org.) Didática da Biologia. Curitiba: Appris, 2017. -a, v.1, p. 13-26.

LIBÂNEO, J. C. Didática. São Paulo: Cortez, 1994, p. 221.

NÓvOA, Antônio. Escola nova. A revista do Professor. Ed. Abril. Ano. 2003, p,23.

UFFS. Projeto Pedagógico do Curso de Ciências Biológicas. UFFS: Chapecó, 2018. 